\title{
What lies beneath: exploring the deeper purposes of feedback on student writing through considering disciplinary knowledge and knowers
}

\author{
Martina van Heerden, Sherran Clarence and Sharita Bharuthram
}

\begin{abstract}
Feedback plays an integral role in students' learning and development, as it is often the only personal communication that students have with tutors or lecturers about their own work. Yet, in spite of its integral role in student learning, there is disagreement between how students and tutors or lecturers perceive the pedagogic purpose of feedback. Central to this disagreement is the role that feedback has to play in ensuring that students produce the 'right' kinds of knowledge, and become the 'right' kinds of knowers within their disciplines. This paper argues that, in order to find common ground between students and tutors or lecturers on what feedback is for, and how to both give and use it effectively, we need to conceptualise disciplinary knowledge and knowers anew. We offer, as a useful starting point, the Specialisation dimension of Legitimation Code Theory as both practical theory and methodological tool for exploring knowledge and knowers in English Studies and Law as two illustrative cases. The paper concludes that this analysis offers lecturers and tutors a fresh understanding of the disciplinary knowledge and knower structures they work within and, relatedly, a clearer view of the work their feedback needs to do within these.
\end{abstract}

\section{Introduction}

Feedback plays an integral role in students' learning and development, because it can make the tacit expectations of a discipline explicit, which aids in students becoming successful learners. Yet, in spite of its integral part in student learning, there is dissonance at times between how tutors or lecturers and students perceive and make use of feedback as a learning tool. There may be misperceptions about the implicit and explicit goals of the discipline in terms of student learning, and, consequently, the pedagogic role feedback should play. These misperceptions can lead to a misalignment of feedback practices to their underlying purpose, and therefore lead to the given feedback being confusing for, or even unusable by, students trying to improve their writing. Much research has been done exploring student perceptions of feedback, as well as how students' and tutors' perceptions may differ on what is considered to be useful and effective feedback (in this study, tutor refers to a senior postgraduate student who facilitates tutorials, which students attend in addition to lectures and other teaching activities). This paper will begin with an overview of the most relevant or widely cited literature exploring tutor and student perceptions of the roles, purposes and methods of giving feedback. These perceptions of feedback are connected to the 
tacit pedagogic purposes of feedback, which also need to be explored. Often there is a difference between what students want and what tutors give as feedback, between tutors' intentions when giving feedback and how students interpret it and between how feedback is given and its intended pedagogical purpose. These differing perceptions of feedback may greatly diminish the effect of feedback as a tool for learning and writing development, and as such, feedback givers, such as lecturers and tutors, may benefit from considering the pedagogic purpose of feedback anew.

Central to a reconsideration of the pedagogical role of feedback is the disciplinary knowledge that students are writing and reading about, and how this knowledge works to shape the space of possibles' (Maton 2014, 7) for what kinds of writing and meaning-making are recognised as valid, and for how valid knowledge can and should be written about. a great deal of feedback research and practice, though, focuses on either improving feedback practices themselves (Huxham 2007; nicol 2010; Hendry, Bromberger, and armstrong 2011), or on how to use feedback to improve student writing (Wingate 2010; vardi 2012). Knowledge in the disciplines may be obscured or only tacitly or partially visible in these considerations. In many instances, research on feedback does not fully consider the concerns of the disciplines in terms of $w$ ho they want their students to become, what they want their students to know or how they want their students to construct knowledge.

This kind of 'knowledge-blindness' (Maton 2014, 4) means that feedback research and practice can risk becoming too generic, and can approach feedback for all disciplines on the basis of issues that may be important to certain disciplines but less important to others, without the tools to articulate why these disciplinary differences may require different feedback practices. This is potentially problematic considering that the overall intention of feedback is to provide students with focused guidance to enable greater epistemic access to disciplinary ways of writing, reading, thinking and creating knowledge. While great strides have been made in recent years to advance teaching and learning in higher education institutions, which in turn has led to more awareness of feedback practices and the need to overcome genericism, tutor training still tends to happen through tutor induction sessions outside of the disciplines. In many cases, senior disciplinary specialists distance themselves from training their tutors, leading to a gap in providing tutors with insight into the specific pedagogical aims of the discipline (Underhill, Clarence-Fincham, and Petersen 2014).

This paper will, therefore, argue that the pedagogic purpose of feedback needs to be reconceptualised, in particular to focus on both knowledge and knowers within the disciplines in order to reconcile differing purposes of feedback, and in so doing, enhance its effectiveness as a tool for learning and development. English Studies and Law will be used as illustrative cases, as these two disciplines provide interesting contrasts: English Studies is a literature course, in which students analyse, and learn how to analyse texts in various contexts (Christie 2015). Success is determined by acquiring the necessary critical eye through which to view texts, as measured through essay writing. Law, on the other hand, is focused on training future legal professionals to both know and use the law in specific technical and procedural contexts, and critical thinking is delimited within this overall focus on procedural proficiency (Clarence 2014). 
Using these disciplines as examples, the paper will enact Legitimation Code Theory's dimension of Specialisation to conceptually explore and articulate the underlying organising principles of these two disciplines in relation to both knowledge and knowers, and then relate these organising principles to the kinds of feedback practices that may best align with them. The first two sections explore current research on feedback before the paper moves on to introduce Specialisation and draw implications for tutors' feedback practices in English Studies and Law, and more widely in higher education.

\section{Perceptions of feedback}

Research into perceptions of feedback has shown that there are common (mis)perceptions about feedback held by both tutors and students. research indicates that many tutors' perceptions about feedback and its effectiveness tend to be negative, with tutors frustrated by what they perceive as 'student indifference to their feedback'(Burke 2009, 41). Tutor-held beliefs of feedback include that 'feedback does not work', or that 'students are more interested in their grade or mark and pay little attention to feedback' (Weaver 2006, 379). Further, tutors' perceptions on how students perceive feedback are linked to how students respond to their assignments. Duncan (2007, 271), for instance, points out that 'a substantial number [of students] do not even bother to collect their work once it has been assessed', suggesting that students are not interested in receiving or using feedback. another common tutor perception of feedback is that students do not read the feedback they are given (McCann and Saunders 2009, 3). Yet, these tutor-held beliefs about feedback have been shown to be context-specific, as many studies have shown that students do look to 'feedback for guidance' (McCann and Saunders 2009, 3) and that feedback is considered to be an 'important and valued component of student learning'(Ferguson 2011, 52). research suggests that students are 'broadly dissatisfied with the [quality of ] written feedback they receive'(dowden et al. 2013, 349). research has also shown that students tend to perceive feedback to be too late (Weaver 2006; Huxham 2007), too general or vague (Higgins, Hartley, and Skelton 2002; Weaver 2006; Huxham 2007), too negative (Weaver 2006), difficult to understand (Chanock 2000; Higgins, Hartley, and Skelton 2001), not detailed enough (Carless 2006), and difficult to act upon (Poulos and Mahoney 2008). Each one of these issues will influence students' willingness and ability to respond to feedback; for instance, if it is too late, students will not have the opportunity to respond to it, whereas if students find feedback too difficult to understand then the potential developmental aspects of feedback will be lost. Moreover, even when students are willing to respond to feedback, they might lack the necessary guidance to do so. Weaver (2006), for instance, found that even though students do value feedback, almost half of the students in her study had not received guidance on how to use it. If students are not able to engage with feedback in a manner that is recognised by tutors (such as rewriting a draft following tutors'suggestions and advice), its potential for encouraging further student development will be lost.

Perceptions of feedback on the part of both tutors and students tend to be rooted in its perceived pedagogic function. adcroft $(2011,414)$, for instance, compared what he terms the 'mythologies of feedback' that students and tutors have, and found that 'there is a gap in understanding and expectations of feedback between academics and students'(408). In particular, his study showed that ' $[t]$ here is significant dissonance as the two groups in the study perceive and interpret the same feedback events in very different ways' (adcroft 2011, 414). He states that: 
academics view feedback as being much more important as a mechanism for, and contributor to, learning than students do and see it as much more powerful in improving performance and changing behaviour than those whom the feedback is intended to help. (adcroft 2011, 416)

This suggests that students and tutors do not necessarily perceive feedback, especially its purpose, in the same manner, which may greatly reduce the intended effect of the feedback. It is thus important to consider the pedagogical purposes of feedback and how these might interplay with perceptions of it.

\section{The pedagogical purposes of feedback}

Broadly speaking, there are two main forms of feedback which correspond to their functions, namely, evaluative feedback and developmental feedback (frequently referred to as summative and formative feedback). Evaluative feedback looks back on a completed task and indicates how successfully a student has completed it, through identifying students' academic strengths and weaknesses (Higgins, Hartley, and Skelton 2002; Weaver 2006). Evaluative feedback may, for instance, tell a student that their conclusion is poor or that their introduction is weak, but does not necessarily explain further or provide advice on how to improve these aspects of his writing. Evaluative feedback may come across as corrective; indeed, correction is one of the subfunctions of evaluative feedback (Ivanič, Clark, and rimmershaw 2000; Price et al. 2010). The problem is that, if feedback only corrects, then it has limited capacity for aiding ongoing student writing development. developmental feedback, on the other hand, has two main subfunctions: developing students' ability to complete future tasks more successfully, and assisting with student development and learning. Ideally, feedback should look forward; that is, it should feed into future assignments (Orsmond et al. 2013). as Crisp $(2007,579)$ points out 'feedback should not only aim to assist students to complete a similar task successfully at some stage in the future, but ideally should also be transferable to other tasks that they might be expected to undertake'. Instead of just correcting errors and/or listing what students have done wrong, feedback should ideally assist students in developing their academic skills. The developmental aspect of feedback is not just limited to assignment completion, but may also apply to students' metacognitive development (Murtagh and Baker 2009), knowledge acquisition (Poulos and Mahoney 2008), as well as potentially leading to behavioural changes in students' approaches to learning (adcroft 2011). Parkin et al. $(2012,963)$ point out that feedback'can be one of the most powerful ways in which to enhance and strengthen student learning'.

However, the developmental aspect of feedback is often not fully realised. For example, evaluative feedback is easier to provide than developmental feedback; it is easier to identify and correct errors than it is to give advice on how to avoid them in the future. Students may also look to feedback as only a corrective tool as they do not necessarily understand the developmental function of feedback. This corrective view of feedback is one legacy of primary and secondary school practices of teaching and learning, as, in most schools, students are not necessarily taught how to produce knowledge of their own, but rather to reproduce knowledge. Kapp $(2006,48)$ points out that, in the South african context, as an example, students have to move from a 'rote-learning mode' in high school to 'engaging in close analysis of texts and in analysing and synthesising multiple points of 
view' at university level. In other contexts, such as the UK, feedback is similarly used in a corrective or instructive manner at school, as knowledge tends to be transmitted from teacher to student in a linear way. This is a result of students being viewed as 'receptacles of transmitted information' in school, whereas at university students are viewed as potentially 'active makers and mediators of meaning within particular learning contexts' (Higgins, Hartley, and Skelton 2002, 53). The feedback given at tertiary level will thus try to overcome a corrective view of feedback.

What underpins both of these functions of feedback is another implicit function of feedback, which is that it is used to 'induct' students into what Lillis $(2001,76)$ calls 'institutional practices of mystery'. academic practices, and specifically writing conventions, tend to be presented as natural and obvious to students by those for whom they are natural and obvious. Feedback is an effective way of inducting students into these practices, yet feedback practices have as much of an obvious, taken-for-granted aspect to them as other academic practices. Moreover, as there is a'dominant subject specific discourse' underpinning feedback (Higgins 2000, 3), it means that tutors give feedback from within a particular disciplinary discourse in order for students to gain access to that discourse, to be inducted and to become successful writers, readers and graduates. Ironically, however, tutors who do not see the discourse as strange or new, and give feedback that does not make the tacit more explicit (Jacobs 2007), may inadvertently alienate students from the very discourse to which they need to gain access and work within. as Bloxham and Campbell (2010, 291) point out:

achieving success as a higher education student, measured essentially through the capacity to write satisfactory assignments and examinations, is perceived as a complex task ... It involves the learning of tacit knowledge, new social practices and forms of expression, and negotiating the meaning and demands of individual assignments with tutors and peers.

For students, then, one of the most important and difficult tasks is navigating their specific disciplines' writing conventions; conventions that tend to stem from not only the knowledge that is being written about and disseminated, but also from the discipline's sense of who its knowledgeable insiders are, and how they represent and further the values and practices of the discipline (Jacobs 2013). Feedback is perhaps best suited to facilitate this navigation, especially since 'face-to-face student-tutor contact time is diminishing, leading to a greater reliance on written correspondence' (Higgins, Hartley, and Skelton 2002, 54). Feedback should ideally not only induct students into academic and disciplinary discourses, but simultaneously make tacit disciplinary academic practices and expectations more explicit. In a discipline like English Studies, where a 'powerful invisible pedagogy often applies, [so] that what is evaluated as success is tacitly understood, rather than clearly articulated'(Christie and Macken-Horarik 2007, 157), feedback thus has an especially important pedagogic role to play in communicating not only what kinds of knowledge count, but also what kinds of knowers successful students need to become.

However, if tutors are not able to critically 'see' and assess the kinds of value they assign or deny to the knowledges students include in their writing, as well as the ways in which they attempt to represent, critique and discuss that knowledge (indicating their development as disciplinary knowers), their feedback giving practices may remain only peripherally useful to those students. 
Tutors therefore need to consider what the pedagogic purposes of the discipline itself are - what specifically are we looking to do with students in our disciplines? do we merely want to create proficient writers focused on learning a set canon of knowledge, or do we want to nurture particular kinds of thinkers or future researchers related to the wider field our disciplines connect with, like academia or legal practice? Tutors thus need to consider what counts as legitimate knowledge in the discipline, as well as legitimate ways of expressing what is known, for it is only by considering what counts as knowledge and knowing in the discipline that they can adequately consider how this may be conveyed to students through feedback.

Conceptualising knowledge as both a subject of study as well as an object of study can be difficult, especially when working with student writing that focuses to a large extent on students'own construction of knowledge, and how they may or may not be doing so in relevant ways. a first step towards connecting feedback with knowledge in the disciplines is to understand knowledge as emerging from socio-historical contexts, but not being reducible to those contexts (Maton and Moore 2010). In other words, while we construct knowledge within our own lived contexts, and therefore it is always fallible, there is an ontologically real world we can know, which makes it possible for us to make intersubjective judgements about knowledge claims (Bhaskar 1998). In relation to the pedagogic aim of feedback as being able to provide students with the means to access, and work successfully within, disciplinary knowledge structures, we need to consider how the knowledge they engage with, and the socio-historical contexts in which it is produced, shape their scholarly or professional identities in particular ways, as well as the written artefacts they produce, such as essays and so on.

Legitimation Code Theory provides us with a conceptual framework that can explore a teaching practice like feedback-giving in a way that enables us to unpack and critically consider the kinds of knowledge, and also the kinds of knowers, valued and developed within the discipline. The following sections will demonstrate how we can use this theory, specifically its dimension of Specialisation, to explore the knowledge and knower structures of Law and English Studies, and consequently expand and better nuance our understanding of the pedagogic purposes of feedback.

\section{Legitimation Code Theory: Specialisation}

Legitimation Code Theory is a conceptual and analytical 'explanatory framework for enactment in and (re-)shaping by substantive research studies' (Maton 2014:15), 'a multidimensional conceptual toolkit for analysing actors' dispositions, practices and contexts, within a variegated range of fields'. These are conceptualised in terms of legitimation codes where 'each "code" represent[s] in effect a currency proposed by actors as the ruler of the field' (Maton 2014, 17-18). In essence, this means that Legitimation Code Theory can uncover and articulate what counts as marking out belonging and not belonging in a specific field. Far from being hegemonic and unchanging, however, these 'currencies' can be challenged and changed; however, before changes can be proposed, we need to be able to articulate the means of establishing legitimacy in the field.

For the purpose of this paper, we will focus on one dimension of the framework, that of Specialisation, which explores the organising principles that denote what makes a field or discipline 'special'. In other words, it conceptualises the underlying principles that legitimate specific practices or forms 
of knowledge, and specific actors and their dispositions (Maton 2014). Specialisation is underlined by the 'simple premise that practices and beliefs are about or oriented towards something and by someone. They thus involve relations to objects and to subjects' (Maton 2014, 29, emphasis added).

Legitimation Code Theory, in drawing an analytical distinction between knowledge and knowers, distinguishes between epistemic relations ( $\mathrm{Er}$ ) and social relations ( $\mathrm{Sr}$ ). Epistemic relations are 'between practices and their object or focus', and are about 'knowledge and its object of study' and focus on 'what is legitimate knowledge' (Maton 2014, 29). In teaching and learning, the emphasis would be on procedural or technical knowledge, and applying this in accepted ways, as one would when preparing legal briefs for court proceedings in Law, for example. Social relations are 'between practices and their subject, author or actor', and are about 'knowledge and its authors/subjects' and focus on 'who is a legitimate knower' (Maton 2014, 29). In teaching and learning, the emphasis would be on modes of thinking, or ways of deconstructing texts and thinking about them, as one would to make a new argument in relation to a set question in English Studies, for example.

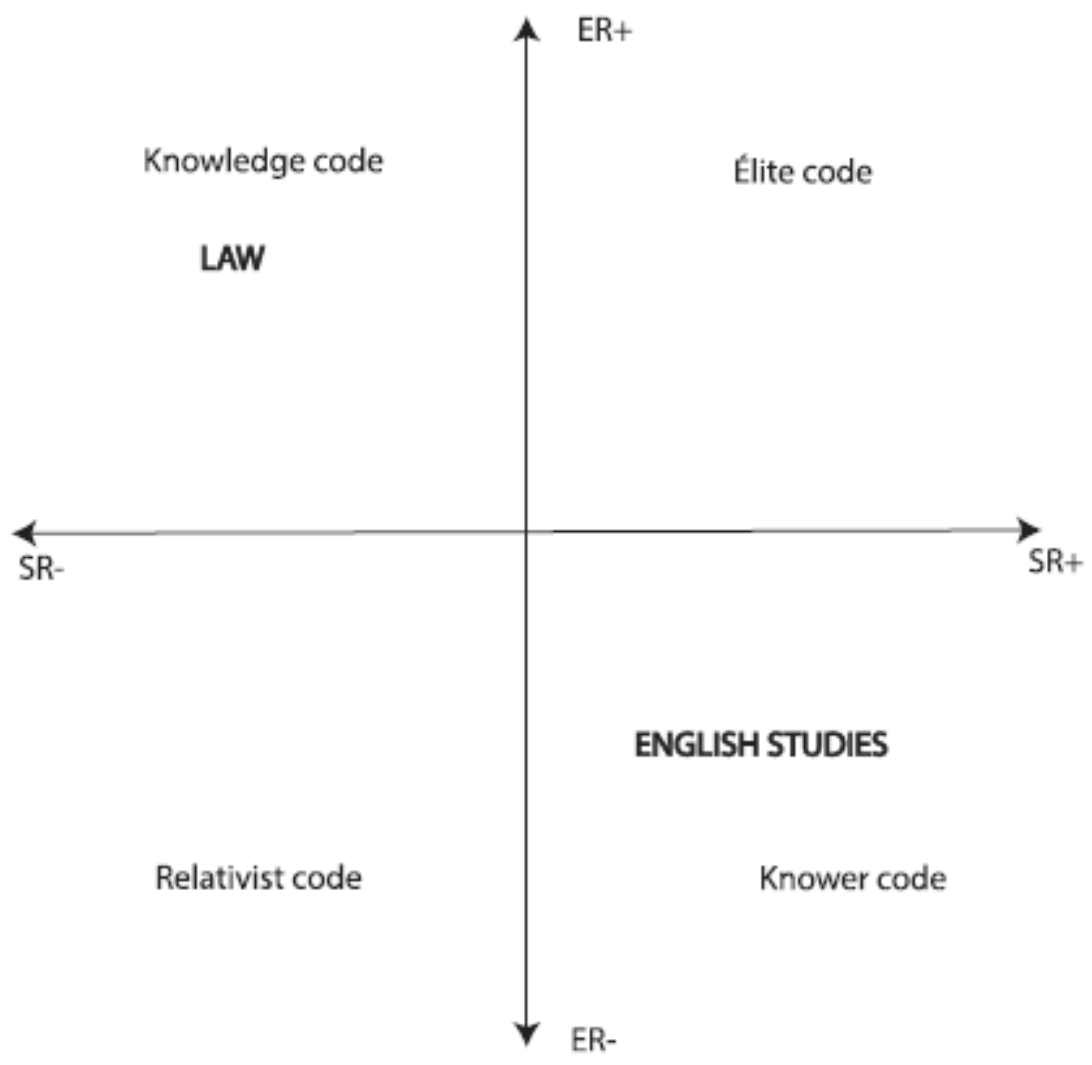

Figure 1. Heuristic specialisation plane for English Studies and Law (cf. Maton 2007, 97).

Combining Er and Sr gives us different specialisation code modalities. Each relation can be stronger or weaker relative to the other, and can be plotted along a continuum of relative positions - this allows for a wide range of possible code modalities to be realised. There are four specialisation codes: 
knowledge codes $(\mathrm{Er}+, \mathrm{Sr}-)$, knower codes $(\mathrm{Er}-, \mathrm{Sr}+)$, élite codes $(\mathrm{Er}+, \mathrm{Sr}+)$ and relativist codes (Er-, Er-), indicated by different relative strengths and weaknesses of $\mathrm{Er}$ and $\mathrm{Sr}$ (see Figure 1). This paper, given English Studies and Law as illustrative cases, explores the implications of giving students feedback within a knower code and a knowledge code, respectively.

It is important to note that Legitimation Code Theory delimits focus and basis in determining the specialisation code. Further, there are always knowers and there is always knowledge, but seldom are the two equally valued in disciplinary teaching and learning practices. Knower codes base 'claims on a legitimate kind of knower. This knower may claim unique knowledge of more than a delimited object of study' (Maton 2014, 32). a knower code emphasises the development of particular dispositional or aptitudinal knowledge, and downplays the learning of particular procedures or techniques by which one develops expertise. In English Studies, teaching and assessment are focused on asking students to read, deconstruct and consider written texts in particular ways. The focus may be on working with texts in particular ways, yet the basis on which student success is judged is not following a particular procedure; rather the basis of success is showing a certain kind of critical, literary, analytical disposition towards knowledge (Christie 2015). It is thus about developing a particular kind of 'knower-ness' in order to cultivate the kinds of thinkers and writers who can legitimately produce knowledge in the field. English Studies may thus be termed a knower code, as it exhibits weaker Er and relatively stronger $\mathrm{Sr}(\mathrm{Er}-, \mathrm{Sr}+)$. Knowledge codes base their claims to legitimacy on knowers grasping and using particular forms of procedural or technical knowledge, downplaying the development of personal aptitudes or characteristics of knowers (Maton 2014). again, the code is determined by the basis for legitimacy rather than the focus. Thus, while the legal curriculum may focus at various different points on students' developing professional aptitudes, or learning legal theory, the basis for recognising them as successful law graduates will, in the end, be their technical skill and ability in researching, reading and utilising the law to reach, using contextually accepted procedures, an evidenced, defensible conclusion, judgement or position (Clarence 2014; Clarence, albertus, and Mwambene 2014). Law can thus be termed a knowledge code, because it exhibits stronger $\mathrm{Er}$ and relatively weaker $\mathrm{Sr}(\mathrm{Er}+, \mathrm{Sr}-)$ (see Figure 1).

In both cases, what is valued as the basis for determining what is legitimated in the discipline can be further conceptualised as a 'gaze'(Bernstein 1999, 165), that students needs to cultivate or develop through training over the course of their studies, and beyond. a significant element of cultivating the gaze in academic disciplines that involve a great deal of writing, such as English Studies and Law, is feedback, either written or oral. Cultivating the desired gaze can be optimally facilitated through feedback, as it can be created as a site of ongoing communication between tutors and students about students' thinking and writing in relation to the underpinning code, which may lead them closer to accessing the discourse and becoming successful knowers in the discipline.

In order for students to be successful knowers in English Studies, they need to develop a cultivated gaze (Luckett and Hunma 2014, 5). It is thus not impossible for students to attain knower-ship of the subject, but it does take time and requires a sustained relationship between students and disciplinary insiders, almost as apprentice and master (Bernstein 1999). The challenge in knower codes that require the cultivation of a gaze is that this relationship is often a tacit one, where 
knowledge is gathered by students along the way, rather than explicitly formulated and relayed through pedagogy (cf. Bernstein 1999). If the process of building towards the ideal knower of English Studies is so time-consuming and tacit, many students may not be able to become the right kinds of knowers within the time allotted to an undergraduate degree. This is further exacerbated if feedback is unable to fully communicate to students, explicitly, what count as the right kinds of dispositions, aptitudes and knowledge within the discipline and the wider institutional context, such that it enables students' ability to understand and more consciously develop these.

English Studies has traditionally had a tacit, but rather powerful 'ideal knower' as its goal, in terms of the aptitude, disposition and character that a student should possess. Christie (1999, 173), for instance, points out that English Studies 'seek[s] to develop pedagogic subjects who take up particular values and adopt particular perspectives upon human activity'. This ideal knower may be constructed by tutors based on their own internalised understanding of what being this knower entails. Tutors' perceptions of the aptitudes, attitudes and dispositions that the 'ideal knower' has to possess may then be filtered through the feedback that students are given, especially since knowerness in English Studies is largely measured through essay writing. However, as this paper posits, the cultivation of this gaze may be interrupted if feedback from tutors miscommunicates the legitimate basis for achievement through focusing, for example, on grammar over students' critical response to a text.

Law, by contrast, tends to value a trained gaze (Clarence 2014), as knowers develop competence through applying their minds to learning and mastering the procedures and principles of legal reasoning and research, and applying these in accepted ways to make and defend arguments. The training of this gaze also takes time, but as the procedures and principles may be codified in relatively explicit ways, it is potentially more open to learning (Maton 2014). Feedback in the case of a trained gaze also needs to communicate the legitimate basis of achievement to students, thus it needs to focus on what is important for students to know and demonstrate. In the case of Law, the feedback needs to be able to guide the development of students' ability to reason through applying and analysing legal statutes, case law and so on. If we consider English Studies and Law through the lens offered by Specialisation - respectively as a knower code that specialises the dispositions and aptitudes of students through cultivating a particular gaze over time, and as a knowledge code that specialises the technical and principled ability and actions of students through training their gaze over time - we can rethink the pedagogical purpose of feedback within these disciplines. This may enable those who read and comment on student writing to move towards a deeper, disciplinefocused understanding of why they give particular forms of feedback, what they would like students to do with that feedback and how they can best use it to develop the gaze legitimated in their discipline over time. In other words, this paper conjectures that, by aligning more explicitly and consciously with a discipline's specialisation code, feedback can better enable access to and successful acquisition of a disciplinary gaze.

In English Studies, students need to demonstrate the "capacity to articulate moral positions and principles by reference to the literary text' (Christie 2015, 159). Further, in a context like South Africa, where curricula are being reformed to reflect current social concerns (guraba 2015), what 
may be further valued is students' ability to articulate critical positions in relation to decolonisation, racism and sexism understood within this context. By seeing these elements of the knower code of this discipline as part of the knowledge and knower structure of the discipline, tutors could adapt the feedback they give students to reference these underlying, tacit aims, more clearly. Tutors, for instance, could use guiding questions (e.g. What specific examples of sexism can you find in the text? Can you relate these to the society or community you live in?) to help students move beyond superficial engagement with a text, and simultaneously help them to develop the necessary critical disposition and gaze. They could, further, explicitly indicate that students need to move beyond personal opinions alone to basing their opinions or positions in relation to literary texts (see Christie 2015), or encourage students to move away from merely reproducing knowledge from the text to a more nuanced production of knowledge about the text.

The questions and dialogue they open up with students through feedback, whether written or oral, could more overtly indicate the values of the discipline in terms of the ways students read, deconstruct, make sense of and reference literature in their own writing. Conversely, if tutor feedback focuses too much on easily corrected aspects, like language use and grammar, it may convey incorrect messages as to what is truly valued in the discipline. Tutors in English Studies thus have to walk a fine line between being language editors and facilitating students' ongoing learning and development.

In Law, what is valued is the ability of students to follow accepted processes of reasoning to solve a range of legal problems in a manner that exhibits clarity of reasoning, accuracy, attention to detail and precise use of terminology (Clarence, Albertus, and Mwambene 2014). Thus, feedback could be tailored to focus less on telling students to construct clear sentences or use correct grammar as arbitrary requirements of writing in English, and could rather focus students on using concise, grammatically correct sentences as being essential to realising clarity of meaning and attention to detail, both important aspects of working in the legal field. as developing procedural and technical knowledge and competence is part of the basis for legitimate achievement in this discipline, tutor feedback could enable students to see where they have gaps in their reasoning, or application of legal statutes or case law, for example. rather than indicating where a student has simply failed to include information, feedback could be refocused, again, to explain to students why leaving such a gap leads to a breakdown in the logic of their argument, thus orienting students to the basis for successful participation in this discipline.

By being able to conceptualise the code of the discipline they work within, specifically the basis for legitimacy that indicates the code and what form this takes in their context, those giving feedback on student writing may be better able to move, whether in giving evaluative or developmental comments, towards more strategic feedback that shows students. This can enable them, more consistently, to indicate what the basis for achievement is, and how students can more consciously acquire the disciplinarygaze.

\section{Conclusion}

Tutors and lecturers in many disciplines tend to walk a fine line between providing evaluative and developmental feedback on student writing. This is especially challenging for tutors and 
lecturers who struggle to articulate clearly what makes student writing successful, what counts as legitimate forms of knowledge and how to demonstrate knowledge through writing. If those giving feedback focus on less important aspects of success in their feedback as a result of this, they may inadvertently miscommunicate the basis for achievement to students, interrupting their consistent growth and development as successful knowers.

Maintaining a balance in feedback between correction and development is also made challenging by a growing awareness that, for some students, the feedback given will not be enough to help them become the right kind of knower. This indicates that there is at times a gap between what feedback should do pedagogically and what it can do in the contexts in which it is given and received. given that the cultivation or training of a gaze that will transform students from novices into experienced knowers is a tacit, lengthy process and can take even more time for students from poorer literacy backgrounds that are not congruent with the literacy demands of higher education (McKenna 2004), we do need to be realistic about what feedback can actually achieve.

This paper contends that feedback has an increasingly important pedagogic role to play in university teaching and learning, as it may be one of the most feasible ways to create authentic knowers in the field, especially in contexts characterised by large classes and many written assignments. However, feedback can only play this role effectively if students and tutors are in agreement with what the pedagogic purpose of feedback is. Thus, the pedagogic purpose of feedback needs to be (re)conceptualised: firstly, to make more explicit that what the discipline requires of students' writing, reading and thinking work is related to the development of a disciplinary gaze; and secondly, to create an effective feedback dialogue between tutor and student that shows students what constitutes the gaze, and guides them in developing it across different levels of study over time. Therefore, if we carefully consider 'what lies beneath'our feedback practices, using a conceptual toolkit like Legitimation Code Theory, and specialisation in particular, we may be better able to show students through our feedback what constitutes valid knowledge and values, relevant

ways of knowing and demonstrating knowledge and how they need to reflect this in their own written, and related reading and thinking, work.

\section{Acknowledgements}

We would like to thank the anonymous reviewers for their useful feedback. no funding was utilised or financial interest gained in undertaking this research.

\section{Disclosure statement}

no potential conflict of interest was reported by the authors. 


\section{References}

Adcroft, a. 2011. "The Mythology of Feedback." Higher Education Research and Development 30 (4): 405-419.

Bernstein, B. 1999. "vertical and Horizontal discourse: an Essay." British Journal of Sociology of Education 20 (2): 157-173.

Bhaskar, r. 1998. "Philosophy and Scientific realism." In Critical Realism Essential Reading, edited by M. archer, r. Bhaskar, a. Collier, T. Lawson, and a. norrie, 16-47. London: routledge.

Bloxham, S., and L. Campbell. 2010. "generating dialogue in assessment Feedback: Exploring the Use of Interactive Cover Sheets." Assessment \& Evaluation in Higher Education 35 (3): 291-300.

Burke, d. 2009. "Strategies for Using Feedback Students Bring to Higher Education." Assessment \& Evaluation in Higher Education 34 (1): 41-50.

Carless, d. 2006. "differing Perceptions in the Feedback Process." Studies in Higher Education 31 (2): 219-233.

Chanock, K. 2000. "Comments on Essays: do Students Understand What Tutors Write?" Teaching in Higher Education 5 (1): 95-105.

Christie, F. 1999. “The Pedagogic device and the Teaching in English."In Pedagogy and the Shaping of Consciousness: Linguistic and Social Processes, edited by F. Christie, 156-185. London: Cassell.

Christie, F. 2015. "Secondary School English Literary Studies: Cultivating a Knower Code.”In Knowledge-building: Educational Studies in Legitimation Code Theory, edited by K. Maton, S. Hood, and S. Shay, 158-175. London: routledge.

Christie, F., and M. Macken-Horarik. 2007. "Building verticality in Subject English." In Language, Knowledge and Pedagogy: Functional Linguistics and Sociological Perspectives, edited by F. Christie and J.r. Martin, 156-184. London: Continuum.

Clarence, S. 2014. "Enabling Cumulative Knowledge-building through Teaching: a Legitimation Code Theory analysis of Pedagogic Practice in Law and Political Science." Phd diss., rhodes University.

Clarence, S., L. albertus, and L. Mwambene. 2014. "Building an Evolving Method and Materials for Teaching Legal Writing in Large Classes." Higher Education 67 (6): 839851. doi:10.1007/s10734-013-9707-8.

Crisp, B. r. 2007. "Is It worth the Effort? How Feedback Influences Students' Subsequent Submission of assessable Work." Assessment \& Evaluation in Higher Education 32 (5): 571-581.

Dowden, T., S. Pittaway, H. Yost, and r. McCarthy. 2013. "Students' Perceptions of Written Feedback in Teacher Education: Ideally Feedback is a Continuing Two-way Communication That Encourages Progress." Assessment \& Evaluation in Higher Education 38 (3): 349-362.

Duncan, n. 2007. “Feed-Forward': Improving Students'Use of Tutors'Comments." Assessment \& Evaluation in Higher Education 32 (3): 271-283.

Ferguson, P. 2011. "Student Perceptions of Quality Feedback in Teacher Education." Assessment \& Evaluation in Higher Education 36 (1): 51-62. 
Guraba, H. 2015. "What is an african curriculum?" Mail \& Guardian Online. accessed 10 February 2016. http://mg.co.za/ article/2015-04-17-what-is-an-african-curriculum

Hendry, g. d., n. Bromberger, and S. armstrong. 2011. "Constructive guidance and Feedback for Learning: The Usefulness of Exemplars, Marking Sheets and different Types of Feedback in a First Year Law Subject." Assessment \& Evaluation in Higher Education 36 (1): $1-11$.

Higgins, r. 2000. “Be More Critical': rethinking assessment Feedback." Paper presented at the British Educational research association Conference, Cardiff.

Higgins, r., P. Hartley, and a. Skelton. 2001. "getting the Message across: The Problem of Communicating assessment Feedback." Teaching in Higher Education 6 (2): 269-274.

Higgins, r., P. Hartley, and a. Skelton. 2002."The Conscientious Consumer: reconsidering the role of assessment Feedback in Student Learning." Studies in Higher Education 27 (1): $53-64$.

Huxham, M. 2007.“Fast and Effective Feedback: are Model answers the answer?”Assessment \& Evaluation in Higher Education 32 (6): 601-611.

Ivanič, r., r. Clark, and r. rimmershaw. 2000. "What am I Supposed to Make of This? The Messages Conveyed to Students by Tutors' Written Comments." In Student Writing in Higher Education: New Contexts, edited by M. r. Lea and B. Stierer, 47-65. Buckingham: Open University Press.

Jacobs, C. 2007. "Towards a Critical Understanding of the Teaching of discipline-specific academic Literacies: Making the Tacit Explicit." Journal of Education 41: 1-24.

Jacobs, C. 2013. "academic Literacies and the Question of Knowledge." Journal for Language Teaching 47 (2): 127-140.

Kapp, r. 2006. "discourses of English and Literacy in a Western Cape Township School." In Academic Literacy and the Languages of Change, edited by Lucia Thesen and Ermien van Pletzen, 30-52. London: Continuum. Lillis, T. M. 2001. Student Writing: Access, Regulation, Desire. London: routledge.

Luckett, K., and a. Hunma. 2014. "Making gazes Explicit: Facilitating Epistemic access in the Humanities.” Higher Education 67 (2): 183-198.

Maton, K. 2007."Knowledge-knower Structures in Intellectual and Educational Fields."In Language, Knowledge and Pedagogy: Functional Linguistic and Sociological Perspectives, edited by Frances Christie and J. r. Martin, 87-108. London: Continuum.

Maton, K. 2014. Knowledge and Knowers: Towards a Realist Sociology of Education. London: routledge.

Maton, K., and r. Moore. 2010. "Introduction." In Social Realism, knowledge and the Sociology of Education. Coalitions of the Mind, edited by Karl Maton and rob Moore, 1-13. London: routledge.

McCann, L., and g. Saunders. 2009. Exploring Student Perceptions of Assessment Feedback. York: The Higher Education academy, Social Policy and Social Work (SWaP report).

McKenna, S. 2004. "The Intersection between academic Literacies and Student Identities." South African Journal of Higher Education 18 (3): 269-280.

Murtagh, L., and n. Baker. 2009. “Feedback to Feed Forward: Student response to Tutors'Written Comments on assignments." Practitioner Research in Higher Education 3 (1): 20-28. 
Nicol, d. 2010. "From Monologue to dialogue: Improving Written Feedback Processes in Mass Higher Education." Assessment \& Evaluation in Higher Education 35 (5): 501-517.

Orsmond, P., S. J. Maw, J. r. Park, S. gomez, and a. C. Crook. 2013."Moving Feedback Forward: Theory to Practice." Assessment \& Evaluation in Higher Education 38 (2): 240-252.

Parkin, H. J., S. Hepplestone, g. Holden, B. Irwin, and L. Thorpe. 2012. "a role for Technology in Enhancing Students' Engagement with Feedback." Assessment \& Evaluation in Higher Education 37 (8): 963-973.

Poulos, a., and M. J. Mahoney. 2008. "Effectiveness of Feedback: The Students' Perspective." Assessment \& Evaluation in Higher Education 33 (2): 143-154.

Price, M., K. Handley, J. Millar, and B. O'donovan. 2010. "Feedback: all That Effort, but What is the Effect?" Assessment \& Evaluation in Higher Education 35 (3): 277-289.

Underhill, J., J. Clarence-Fincham, and n. Petersen. 2014. "developing a Mentorship Programme for Junior Lecturers Working with Student Tutors at a South african University: Emerging Shifts in Pedagogy and Identity." Education as Change 18 (2): 357-371.

Vardi, I. 2012. "The Impact of Iterative Writing and Feedback on the Characteristics of Tertiary Students' Written Texts." Teaching in Higher Education 17 (2): 167-179.

Weaver, M. r. 2006."do Students value Feedback? Student Perceptions of Tutors'Written responses." Assessment \& Evaluation in Higher Education 31 (3): 379-394.

Wingate, U. 2010. "The Impact of Formative Feedback on the development of academic Writing." Assessment \& Evaluation in Higher Education 35 (5): 519-533. 